\title{
Introduzindo objetos de aprendizagem no processo de ensinar e aprender Cálculo Diferencial e Integral
}

\author{
Maria Cristina Kessler \\ UNISINOS \\ mkessler@unisinos.br
}

\begin{abstract}
Resumo
O presente trabalho relata as estratégias de ensino que vem sendo desenvolvidas na UNISINOS por um grupo de professores com o objetivo de impulsionar a aprendizagem dos acadêmicos nas disciplinas de Cálculo Diferencial e Integral. Dentre essas estratégias, destaca-se o desenvolvimento de material didático na forma de CD-ROM. O trabalho relata também análises de um estudo investigativo que buscou validar esta produção, a partir da compreensão de como se dá o processo de ensino-aprendizagem da matemática na universidade, mediado por esses objetos.
\end{abstract}

Palavras-chave: matemática, ensino-aprendizagem, multimídia, objeto de aprendizagem.

\begin{abstract}
This paper reports the education strategies that are being developed at UNISINOS by a group of professors with the aim of improving student's mathematic learning. Amongst these strategies, the development of didactic material in the CD-ROM form is distinguished.

This work also presents results of the current research that propose to validate this production, from the understanding of how occurs the process of teach-learning of the mathematics at the University using digital material.
\end{abstract}

Key words: Mathematics - learning - digital material -

Introdução

Muitas são as modificações ocorridas no perfil do aluno que ingressa na universidade. O que se observa hoje não é mais um corpo discente constituído basicamente por jovens entre 18 e 22 anos, recém saídos do ensino médio. A população estudantil apresenta uma faixa etária bastante ampla, com grande número de alunos de idade superior a 30 anos, e muitos deles há tempo fora da escola. São alunos trabalhadores, alguns já com famílias constituídas, o que reduz de forma expressiva o tempo de dedicação ao estudo, aspectos importantes no entendimento da evasão e da repetência no ensino superior.

Esta ampla diversidade se traduz de diversas formas. Não são diferenças apenas de perspectivas e interesses entre os universitários, mas também de estilos e condições de aprendizagem centradas em também diferentes relações com os saberes (Charlot, 2001; 
Douady,1995). Estes aspectos impõem mudanças, inovações na prática pedagógica do professor universitário, exigindo revisão de mitos e preconceitos relacionados à docência no terceiro grau, considerada, por muitos profissionais, de pouca importância.

Outro aspecto a considerar são as lacunas que grande parte dos alunos traz do ensino médio, especialmente aquelas relacionadas à matemática, foco deste estudo, fato que não é compreendido por grande parte dos docentes universitários.

Na minha compreensão, a universidade, ao receber os alunos por ela selecionados, assume perante os mesmos um compromisso com sua formação, o que implica em uma busca constante de alternativas educacionais ajustadas às aspirações e aos estilos de aprendizagem desses alunos.

Essas considerações, aliadas à compreensão de que o envolvimento do aluno com o saber é influenciado expressivamente pela forma como esse conteúdo lhe é apresentado, levou um grupo interdisciplinar de professores da UNISINOS a propor o desenvolvimento de material didático digital, a ser disponibilizado na forma de CDROM, cujas características permitem considerá-lo objeto de aprendizagem (OE).

Cabe referir que a opção pela distribuição do material em CD-ROM vincula-se ao fato de que muitos dos nossos alunos têm computadores em casa, mas não têm acesso a INTERNET.

O projeto, denominado Ensino Propulsor, busca, através de determinadas ações que privilegiam a lógica do aluno, seu conhecimento prévio, sua história, sua relação com os diferentes saberes, impulsionar a sua aprendizagem na Universidade, com vistas à diminuição dos índices de repetência continuada e evasão que nela ocorrem.

O grupo, que iniciou esta atividade em 2005, atua nas áreas de matemática, física, química e português e, além da produção/organização de material didático em CDROM, para estudo a distância, desenvolve ações e realiza um acompanhamento sistemático do processo de aprendizagem do aluno, tanto na forma presencial, como a distância, via e-mail e MSN.

Este texto, além de apresentar os pressupostos teóricos metodológicos envolvidos na produção de objetos voltados à melhoria da aprendizagem do Cálculo Diferencial e Integral na UNISINOS, apresenta também resultados de um estudo investigativo desenvolvido para avaliar em que medida este objetivo foi alcançado.

1- Algumas premissas acerca do material produzido:

A produção do OE pautou-se na análise das produções dos alunos em testes e provas ao longo de alguns anos. Estas análises apontaram uma série de dificuldades apresentadas pelos alunos, ratificando estudo anterior (Kessler e Fischer, 1999) que realizou um mapeamento destas dificuldades, dentre as quais se destacam: dificuldade em formular hipóteses, falta de domínio da linguagem matemática e da própria língua materna, raciocínio lógico pouco desenvolvido, dificuldades na compreensão e manipulação dos conceitos matemáticos, na avaliação de suas produções intelectuais, na leitura/interpretação de gráficos e tabelas. 
Estas análises prévias são extremamente importantes para o processo de ensinoaprendizagem e para a produção das situações didáticas, na medida em que permitem que se conheçam as estruturas de recepção dos alunos.

$\mathrm{Na}$ produção dos objetos de aprendizagem para o Cálculo, alguns aspectos foram priorizados: ludicidade, linguagem acessível, contextualização, interatividade, inclusão de conteúdos do ensino básico.

\subsection{O lúdico}

Não há consenso, entre os professores universitários, sobre a importância do lúdico no processo de ensino-aprendizagem dos estudantes. Não se trata simplesmente de motivar os alunos, mas de desenvolver diferentes estratégias que possam contemplar as diferentes formas de aprender, vivenciadas pelos estudantes. Isto não significa, como destaca Foresti (1995), "desprezar a cultura linear, cartesiana, característica da civilização ocidental (...) mas integrá-la a essa nova forma de ver o mundo, em que: fala-se mais do que se escreve; vê-se mais do que se ouve; sente-se antes de compreender" (p. 4).

Contemplando a questão do lúdico, o objeto apresenta cores, imagens, movimentos, animações, links e vídeos, de forma a despertar o interesse do aluno sem abrir mão do questionamento, do desafio. $\mathrm{O}$ caráter dinâmico do Cálculo acabou impondo a construção e inserção de animações e simulações. Esta característica é extremamente importante, visto que os conceitos normalmente são apresentados ao aluno apenas com a utilização do quadro verde e giz, o que dificulta a compreensão.

Uma destas situações (Fig. 1) mostra o que acontece com a declividade de uma reta secante quando $\Delta \mathrm{x} \rightarrow 0$. Quando o aluno navega pela tela e passa o cursor sobre a palavra "movimento" pode observar, além do deslocamento de um ponto vermelho sobre a curva, a reta secante à curva tendendo a uma reta tangente.

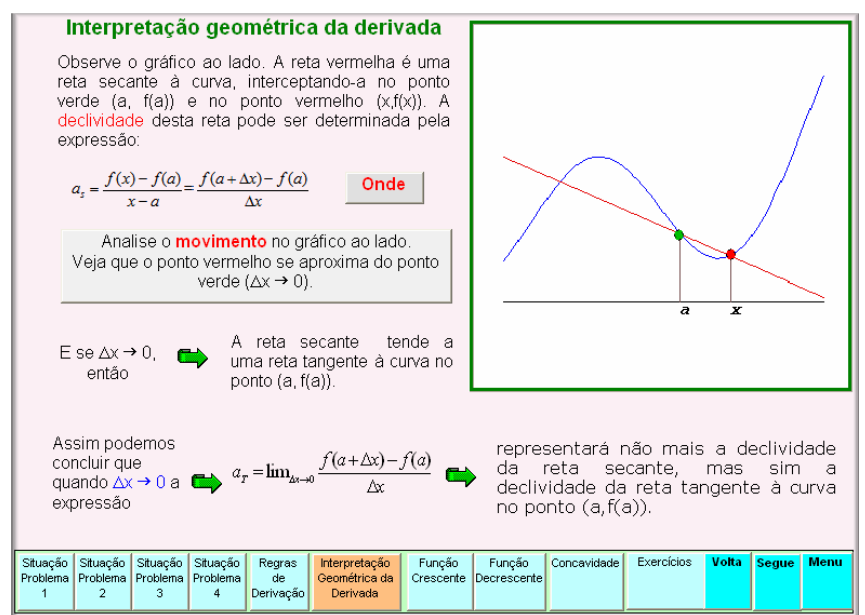

Fig. 1 - Interpretação geométrica da derivada

1.2 - A linguagem

A utilização de uma linguagem acessível na produção dos OE é de extrema importância, visto que o repertório vocabular da maioria dos alunos é bastante restrito, não coincidindo com o padrão escrito e oral esperado pela universidade. 
A linguagem tem importante papel na medida em que se constitui um instrumento de mediação do sujeito com o mundo e, no caso específico, da produção de material didático digital. Neste sentido é preciso estar atento à questão trazida por Vygotsky (1989), que enfatiza:

[...] a comunicação por escrito baseia-se no significado formal das palavras e requer um número muito maior de palavras do que a fala oral, para transmitir as mesmas idéias. Dirige-se a um interlocutor ausente, que muito poucas vezes tem em mente o mesmo assunto que o escritor (p.122).

Como se trata de uma produção escrita, faz-se necessário lançar mão de recursos que destaquem determinados aspectos que, nas aulas presenciais, são indicados por gestos, mudanças de voz, informações complementares. Dentre os recursos utilizados cabe citar: mudanças de estilo e tamanho das letras, janelas com informações adicionais, links com conteúdos afins, etc.

Nossa opção foi pela utilização de uma linguagem mais enxuta, mais informal do que aquela normalmente utilizada nos livros didáticos, e semelhante àquela utilizada nas aulas presenciais.

Há que se destacar, também, que a matemática é uma área de conhecimento que possui uma linguagem própria, que veicula determinados códigos. Nesse sentido, a linguagem utilizada no material produzido vai se modificando, de forma gradativa, promovendo a familiarização do aluno com os códigos dessa área de conhecimento.

\section{3 - Contextualização}

O material produzido trata os conceitos de forma contextualizada, a partir de situaçõesproblema vinculadas aos interesses e à prática social do aluno, destacando os aspectos científicos, sociais e históricos que possibilitaram determinadas sínteses.

Para Meirieu (1998), uma situação-problema pode assim ser definida:

É uma situação didática na qual se propõe ao sujeito uma tarefa que ele não pode realizar sem efetuar uma aprendizagem precisa. Esta aprendizagem, que constitui o verdadeiro objetivo da situação-problema, se dá ao vencer o obstáculo na realização da tarefa (p. 192).

As situações-problema caracterizam-se pela vinculação com a realidade do aluno, pela mobilização de recursos que desafiam a superar obstáculos. Trata-se, portanto, de um contexto que desequilibra visando a problematização dos conceitos.

Com o objetivo atribuir significado, os conteúdos são desenvolvidos também considerando a historicidade do objeto em estudo. Tal abordagem possui particular importância no âmbito pedagógico, uma vez que, através da História, são apresentados modelos, conceitos, obstáculos epistemológicos, elementos que constituem o processo de produção de conhecimento, além de enfocar fatores socioculturais que foram determinantes nesta produção.

De acordo com Vasconcelos, "resgatar a história do conhecimento ajuda a re-significálo, na medida em que se entende em que contexto surgiu e que tipo de problema veio resolver, etc." (p. 110). 
Um exemplo que ilustra esta compreensão pode ser visualizado na figura 2 . Trata-se de uma animação que aborda o paradoxo de Zenão, que traz em seu bojo algumas das idéias relativas ao conceito de limite, um dos fundamentos do Cálculo, veiculadas por volta de 450 anos a.C. Com um clique se pode observar o percurso de um sapinho deslocando-se de um ponto a outro, de modo que a distância a percorrer seja sempre a metade da distância percorrida no instante anterior.

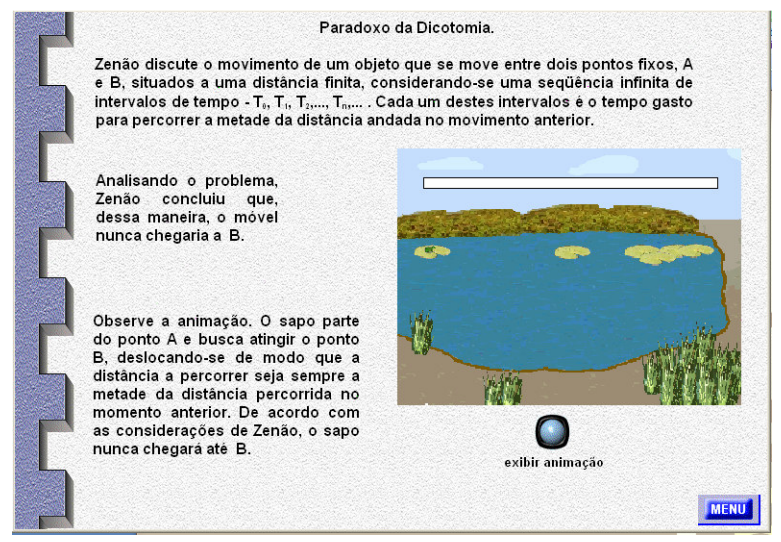

Figura 2 - Paradoxo de Zenão: Dicotomia

\section{4 - Interatividade}

Entende-se por interatividade a possibilidade, agregada à evolução das novas tecnologias, da transformação dos sujeitos envolvidos na comunicação, de meros receptores, para também emissores (Lévy,1999). Neste sentido, a interatividade não se restringe à possibilidade do receptor de navegar espontaneamente pelas sessões dos programas, mas representaria a possibilidade de atribuição de novos significados à informação, para reconstruí-la, de forma ativa e crítica, pelo usuário. Ou seja, interatividade seria a interferência do usuário sobre os meios, produzindo outros textos portadores de suas reflexões e conclusões.

Nesta perspectiva, a interatividade se constitui em característica essencial nos $\mathrm{OE}$ produzidos pelo Ensino Propulsor, uma vez que para que haja uma aprendizagem significativa é necessário envolvimento ativo do aluno no processo de aprender, a partir de situações desafiadoras que levem o aluno a formular e reformular hipóteses. Desta forma, entende-se que o material produzido precisa: provocar, dispor e interagir (Vasconcelos, 2002).

Provocar no sentido de fazer o aluno pensar, refletir. A intenção é produzir material que estimule o aluno a rever suas concepções prévias, provocando desequilíbrios na sua estrutura cognitiva, elemento importante na aquisição de novos conhecimentos.

Dispor no sentido de dar indicações, oferecer subsídios. Dispor objetos, elementos, situações. De acordo com Vasconcelos (2002) "dar condições para que o educando tenha acesso a elementos novos, para possibilitar a elaboração de respostas aos problemas suscitados, superar a contradição entre sua representação e a realidade" (p. $105)$.

E, como terceira ação importante, o material produzido busca uma interação com a representação do aluno. A aprendizagem, como enfatiza Meirieu (1998), "exige uma 
ruptura com antigas representações ou preconceitos anteriores. Requer, portanto, uma intervenção externa ou uma situação específica que obrigue o sujeito a modificar o seu sistema de pensamento" (p. 31). Estas intervenções buscam provocar um desequilíbrio na estrutura cognitiva dos alunos, fazendo-os avançar no sentido de uma nova e mais elaborada reestruturação.

A figura 3 mostra a simulação de uma experiência na qual uma mola é distendida quando submetida a diferentes pesos. O usuário clica sobre um dos pesos, que, uma vez acionados, se movem colocando-se sobre o prato e distendendo a mola. Esta experiência, além de desafiar o aluno a construir modelos, lhe impõe lidar com tabelas e diferentes representações, tanto na forma algébrica como gráfica.

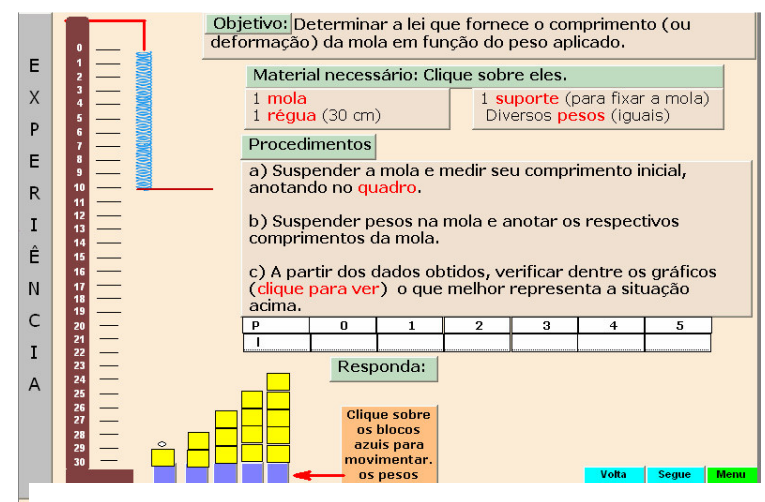

Figura 3 - Experiência da mola

Além das características evidenciadas, o material produzido apresenta outras, que na compreensão de Lemos (2008) vão marcar a interatividade entre os usuários e o material produzido em mídias digitais: Feedback imediato, interação de forma individualizada, manipulação do conteúdo da informação.

Uma das características importantes do material produzido é a verificação, por parte do aluno, do seu desempenho. A cada resposta do aluno, uma mensagem lhe é enviada. Em caso de erro lhe é enviada uma mensagem de estímulo, do tipo "tente novamente", além de respostas problematizadoras, que têm como objetivo auxiliar o aluno a rever suas concepções prévias. Entendemos que se as representações iniciais forem apenas rejeitadas, o sujeito adquirirá somente a ilusão do saber e as velhas concepções ressurgirão na primeira oportunidade. Essas respostas problematizadoras que compõem o material didático produzido abordam os erros mais freqüentes dos alunos, tais como divisão por zero, ordem de prioridade das operações, a existência do limite em um ponto onde a função não é definida, entre outros.

1.5 - A inclusão de conteúdos do ensino básico

Outro aspecto importante a destacar são as dicas. O material produzido contém "janelas", identificadas no texto em vermelho, que permitem que conceitos desenvolvidos anteriormente, ou ainda nos níveis de ensino anteriores, possam ser retomados, minimizando possíveis lacunas na formação do aluno, conforme indicado na figura 4. Os aspectos acima descritos permitem que o aluno construa um caminho próprio, de modo a contemplar as especificidades do seu processo de aprendizagem. 


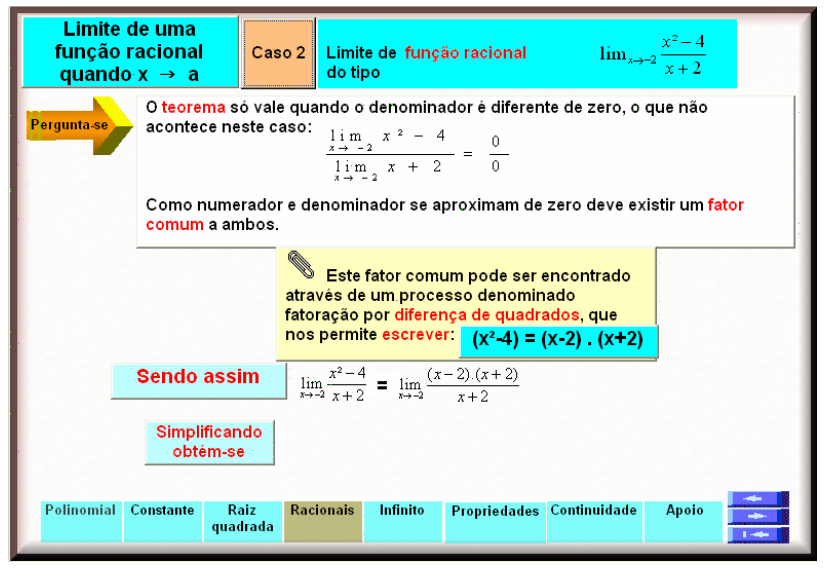

Figura 4 - Dicas

A inclusão de temas do ensino médio no terceiro grau não é vista de forma consensual por muitos professores universitários. Alguns se negam a tratar, em suas salas de aula, assuntos da escola fundamental e média, argumentando que não é esta a função da universidade.

No meu entendimento o papel da universidade também está sendo repensado, na medida em que os acadêmicos de hoje têm pouco em comum com o jovem recém saído do ensino médio, sobre o qual foi estabelecido o modelo das universidades públicas brasileiras (Paiva e Warde, 1994).

2 - Implementação

Durante a fase de produção pela equipe do Ensino Propulsor, acadêmicos inseridos no projeto eram solicitados para avaliar o material em construção. Tal solicitação pretende contribuir para minimizar as dificuldades, que algumas vezes surgem, pelo fato de o docente transmitir um saber a partir de sua própria lógica, que por sua vez é interpretado pelos alunos a partir de seu próprio sistema de referências.

O material digital foi construído inicialmente utilizando-se os softwares Toolbook e Macromedia Flash [Adobe, 2006]. Este último assumindo a produção de forma mais expressiva pelas vantagens que apresenta: facilidade de utilização, tamanho reduzido do produto final, portabilidade, velocidade na construção de aplicações fortemente interativas, integração com XML e HTML e possibilidade do uso de frameworks e componentes. Trata-se de uma tecnologia de aprendizado rápido e fácil, apresentando uma linguagem de scripts simples e poderosa, o que torna o processo de desenvolvimento mais rápido se comparado ao toolbook.

\section{3 - Experimentação}

Os sujeitos do estudo desenvolvido são alunos de duas turmas noturnas de Cálculo A da UNISINOS. Os critérios de escolha dos participantes da investigação foram os seguintes: dificuldades com a matemática, disponibilidade e interesse em usar o material produzido.

4 - Validação dos Objetos de aprendizagem 
O estudo investigativo buscou a compreensão do processo de ensino-aprendizagem do Cálculo, a partir da utilização de material didático em multimídia. Neste sentido, o estudo se propôs a responder às seguintes questões: Qual o impacto do material produzido na aprendizagem significativa da matemática? As situações didáticas propostas no CD-ROM favorecem a compreensão dos conceitos matemáticos? Como o acadêmico interage com o material didático produzido?

Os dados utilizados na pesquisa foram obtidos a partir de observações realizadas na sala de aula; relatos dos alunos; instrumentos de avaliação que buscavam aferir o desenvolvimento das competências propostas; avaliação realizada pelo aluno sobre o material produzido.

Apesar da análise do material coletado não estar totalmente concluída, cabe destacar alguns resultados preliminares:

\section{1 - Boa receptividade do material pelo acadêmico}

A opção por desenvolver material didático em multimídia despertou interesse e curiosidade nos alunos, como se pode observar a partir dos seguintes depoimentos ${ }^{1}$ :

"A forma em que é passada a matéria, se percebe no mesmo um aprendizado brincando" (Cleo, turma 23).

“Clareza nas explicações, desenvolvimento do conteúdo" (Bernardo, 23).

"Ele é bem prático, daí fica mais fácil de estudar" (Guilherme, turma 43).

Um dos elementos que elevaram o interesse do aluno foram os vídeos. Um exemplo a ser descrito refere-se à apresentação das condições que determinam a continuidade de uma função. Como introdução ao assunto foram apresentados aos usuários vídeos que continham erros de descontinuidades de filmes famosos como, "Gladiador" e "Onze homens e um segredo".

\section{2 - Auxílio na compreensão dos conceitos}

Os acadêmicos destacam elementos importantes contidos no $\mathrm{CD}$ que auxiliaram na aprendizagem do cálculo, tais como a interatividade, a linguagem acessível e as aplicações práticas, conforme os relatos a seguir:

"Muito bem explicado o conteúdo" (Cris, 33)

"Forma muito clara de expor o conteúdo, principalmente através das animações".

“Ótimo auxílio na aprendizagem, principalmente as vizualizações (sic) em movimento como por exemplo, nos gráficos" Tânia (turma 23)

Esta aluna refere-se a uma animação construída com o objetivo de auxiliar na leitura de gráficos, mais especificamente, à obtenção do domínio e imagem de uma função, uma das dificuldades apontadas por grande parte dos alunos nas análises prévias.

\footnotetext{
${ }^{11}$ Os sujeitos da pesquisa são descritos a partir de nomes fictícios e os depoimentos transcritos tais como foram coletados.
} 
O feedback também mereceu destaque por parte dos acadêmicos:

"Destaco a maneira criativa com que o conteúdo é apresentado, fazendo uso de animações, cores e situações problemas que nos levam a associar o conteúdo à realidade. Outro ponto que julgo muito positivo são os exercícios com respostas permitindo a avaliação imediata quanto ao aprendizado" (Eduardo).

\section{3 - Mudança da relação com o saber matemático}

Um dos pressupostos que perpassam o processo de produção de OE, já destacado anteriormente, vincula-se ao fato de que as pessoas estabelecem diferentes relações com o saber matemático, diferentes daquelas que normalmente são induzidas ao aluno pelas instituições de ensino, e que estas relações são dinâmicas, podem ser modificadas a partir de situações que façam sentido para o aluno. Os depoimentos dos alunos reforçam estas afirmações:

"Entrei na disciplina de Cálculo A, com muitas deficiências provenientes do Ensino Médio, e não tinha interesse por nenhum assunto relacionado à Matemática. Depois de conhecer o teu jeito de transmitir o conhecimento eu reformulei boa parte dos meus conceitos sobre ensinar e aprender. [...] Pude sanar dúvidas antigas e aprender muitas coisas novas e, principalmente, me interessei pelos desafios propostos em cada aula. Pena que não tive tempo suficiente para praticar os exercícios e obter uma nota maior" (Carlos).

"Quero dizer para senhora que passei a ver a matemática com outros olhos a partir de agora, eu já gostava, mas com tuas aulas, comecei a amar essa matéria” (Pedro).

De acordo com Douady (1995):

En efecto, uma modificación de las relaciones de estos estudiantes con las matemáticas implica que los contenidos de esta disciplina y la disponibilidad de herramientas de manejo bajo su control tomen um significado diferente. Esto requiere que los estudiantes puedan entrar em uma actividad intelectual y que ellos estén convencidos de que esto vale la pena, no sólo desde el punto de vista social y cultural (p. 67).

Cabe referir que o OE produzido foi também utilizado e problematizado em aula, o que elevou o grau de interesse dos alunos pela matéria.

4.4 - Satisfação do aluno:

"Gostaria de parabenizar a pessoa ou grupo que produziu o $\mathrm{CD}$. Ele é muito útil e fácil de usar. Obrigado por sua dedicação ao nosso aprendizado". Egon

"Tenho grande dificuldade na interpretação matemática. O CD tem me ajudado muito com isto". Tarcísio

\section{Considerações finais}

Finalizando é importante referir que as ações relatadas, focalizando a produção de material em multimídia, além de colaborar na aprendizagem do Cálculo, contribuem também com a problematização dos processos de ensinar e aprender no terceiro grau, na 
medida em que propõe uma reorganização de tempos e espaços e o acolhimento do acadêmico, tratado e considerado a partir de suas individualidades e interesses.

Referências Bibliográficas:

Charlot, Bernard (2001). Os jovens e o saber: perpectivas mundiais. Artmed Editora, Porto Alegre.

Douady, Régine (1995). La ingeniería didáctica y la evolución de su relación con el conocimiento. En Artigue, M; Douady, R; Moreno, 1; Gómez, P. Ingeniería didáctica em educación matemática. Grupo Editorial Iberoamérica, Bogotá.

Foresti, Miriam Celi Pimentel Porto. Prática docente na universidade: a contribuição dos meios de comunicação. IN: Tecnologia Educacional, V. 22 (125), Jul/Ago, 1995.

Kessler, Maria Cristina. Fischer, Maria Cecilia B. (1999). Desenvolvendo habilidades cognitivas através da matemática. En Anais da $22^{a}$ Reunião Anual da Associação Nacional de Pós-Graduação e Pesquisa em Educação (ANPEd), Caxambu-MG.

Lemos, André. Anjos interativos e retribalização do mundo: sobre interatividade e interfaces digitais. Disponível em:

http://www.facom.ufba.br/pesq/cyber/lemos/interac.html Acessado em 08/06/2008.

Lévy, Pierre (1999): Cibercultura. São Paulo: Editora 34.

Meirieu, Philippe. Aprender sim... mas como? Porto Alegre: Artmed Editora, 2002.

Paiva, Vanilda. Warde, Mirian Jorge (orgs). Dilemas do ensino superior na América Latina. Campinas, SP: Papirus, 1994.

Vasconcellos, Celso dos Santos (2002). Construção do conhecimento em sala de aula. Libertad, São Paulo.

Vygotsky, L. S. (1989). A Formação Social da Mente São Paulo: Martins Fontes 